\title{
Study of the Mobility of Some Metallic Trace Elements (MTEs) of Certain Lowlands of the City of Daloa (Côte d'Ivoire)
}

\author{
Yapi Yapo Hermann Arsitide ${ }^{1}$, Gouli Bi Irié Marc ${ }^{2,}$, Kouyaté Amadou ${ }^{1}$, Diby Brou ${ }^{1}$, \\ Dongui Bini Kouamé ${ }^{1}$, Trokourey Albert ${ }^{2}$ \\ ${ }^{1}$ Department of Mathematics, Physics, Chemistry and Computer Science, Jean Lorougnon Guédé University, Environmental Training and \\ Research Unit, Laboratory of Environmental Sciences and Technology, Daloa, Côte d'Ivoire \\ ${ }^{2}$ Training and Research Unit of Structural Sciences of Matter and Technology, Université Félix Houphouët-Boigny, Physical Chemistry \\ Laboratory, Abidjan, Côte d'Ivoire
}

Email address:

marcgoulibi@gmail.com (G. Bi I. Marc)

${ }^{*}$ Corresponding author

\section{To cite this article:}

Yapi Yapo Hermann Arsitide, Gouli Bi Irié Marc, Kouyaté Amadou, Diby Brou, Dongui Bini Kouamé, Trokourey Albert. Study of the Mobility of Some Metallic Trace Elements (MTEs) of Certain Lowlands of the City of Daloa (Côte d'Ivoire). American Journal of Applied Chemistry. Vol. 9, No. 4, 2021, pp. 102-108. doi: 10.11648/j.ajac.20210904.12

Received: June 23, 2021; Accepted: July 21, 2021; Published: August 5, 2021

\begin{abstract}
Metallic Trace Elements (ETM) are naturally transported to the shallows by runoff. As the lowlands are exploited for market gardening, ETM can be found in the products of these crops and present risks of contamination for the populations. It is with this in mind that we decided to study the mobility of metallic trace elements in the soils of the market garden lowlands of the city of Daloa. To achieve this goal, nine (9) soil samples were taken from 3 sites at different depths $(0-15 \mathrm{~cm}, 15$ to $30 \mathrm{~cm}$ and more than $30 \mathrm{~cm})$. The determination of the water $\mathrm{pH}$ and of the organic fraction of the sediments were carried out according to ISO 10390 and NF ISO 10694 standards respectively. The ETM contents were obtained by an Atomic Absorption Spectrometer (AAS). The results obtained showed that the majority of the sediments studied are acidic. In addition, they contain a more or less large organic fraction of between 10 and $50 \%$. In addition, our studies demonstrated a mobility of certain ETMs, in particular $\mathrm{As}, \mathrm{Cr}, \mathrm{Hg}$ and $\mathrm{Zn}$, depending on the different sediment profiles studied. Also, $\mathrm{Cd}, \mathrm{Cr}, \mathrm{Mg}, \mathrm{Ni}, \mathrm{Pb}$ are linked to organic matter and to the clay fraction of the sediments. However, their mobility would be influenced by $\mathrm{pH}$.
\end{abstract}

Keywords: Mobility, Metallic Trace Elements Organic Matter, Sediments, Lowlands, Vegetable Crops

\section{Introduction}

Since the end of the 20th century, Africa has experienced rapid population growth and urbanization. As food needs are growing, the rural world is no longer able to respond effectively to the food issue because of unfavorable bioclimatic conditions, rural exodus and land issues.

Intra-urban agriculture, and in particular market gardening, therefore presents itself as an important alternative to guarantee food security. Its proximity to the city, its accessibility at any time of the year, its responses adapted to the eating habits induced by urbanization and the westernization of African populations, make this market gardening the most important value chain favorable to nutrition [1].

In the Ivory Coast, and more particularly in Daloa, the population maintains more or less close relations with the lowlands. They are the subject of numerous hydroagricultural developments throughout the year as the rice fields succeed market gardening. In addition, the shallows are used for household purposes (laundry, dishes) or for fun (swimming, fishing) [2].

In addition, certain districts of the city of Daloa directly discharge their waste water there, which contains metallic trace elements (MTE) without having previously treated it. Also, MTEs are naturally channeled to the lowlands by 
runoff. Once in the soil, metallic trace elements are not very prone to migrations and often accumulate on the surface [3]. They can also change shape or migrate to other constituents of the soil or to the liquid phase depending on the physicochemical conditions. These changes make MTEs more or less mobile in soils and more or less available to the biosphere [4]. In addition, being exploited for market gardening, MTE can be found in the products of these crops and present risks of contamination for the populations.

Hence the object of this study, which is a contribution to the study of the mobility of MTE in the lowlands of the city of Daloa by highlighting factors including $\mathrm{pH}$ and organic matter that influence their mobility.

\section{Materials and Methods}

\subsection{Sampling}

The soil sampling consisted of taking a systematic sample from each plot using an auger. On each site, we took three samples at different depths for P1 (0 to $15 \mathrm{~cm})$, for P2 (15 to $30 \mathrm{~cm}$ and P3 (> to $30 \mathrm{~cm}$ ). For each soil horizon.

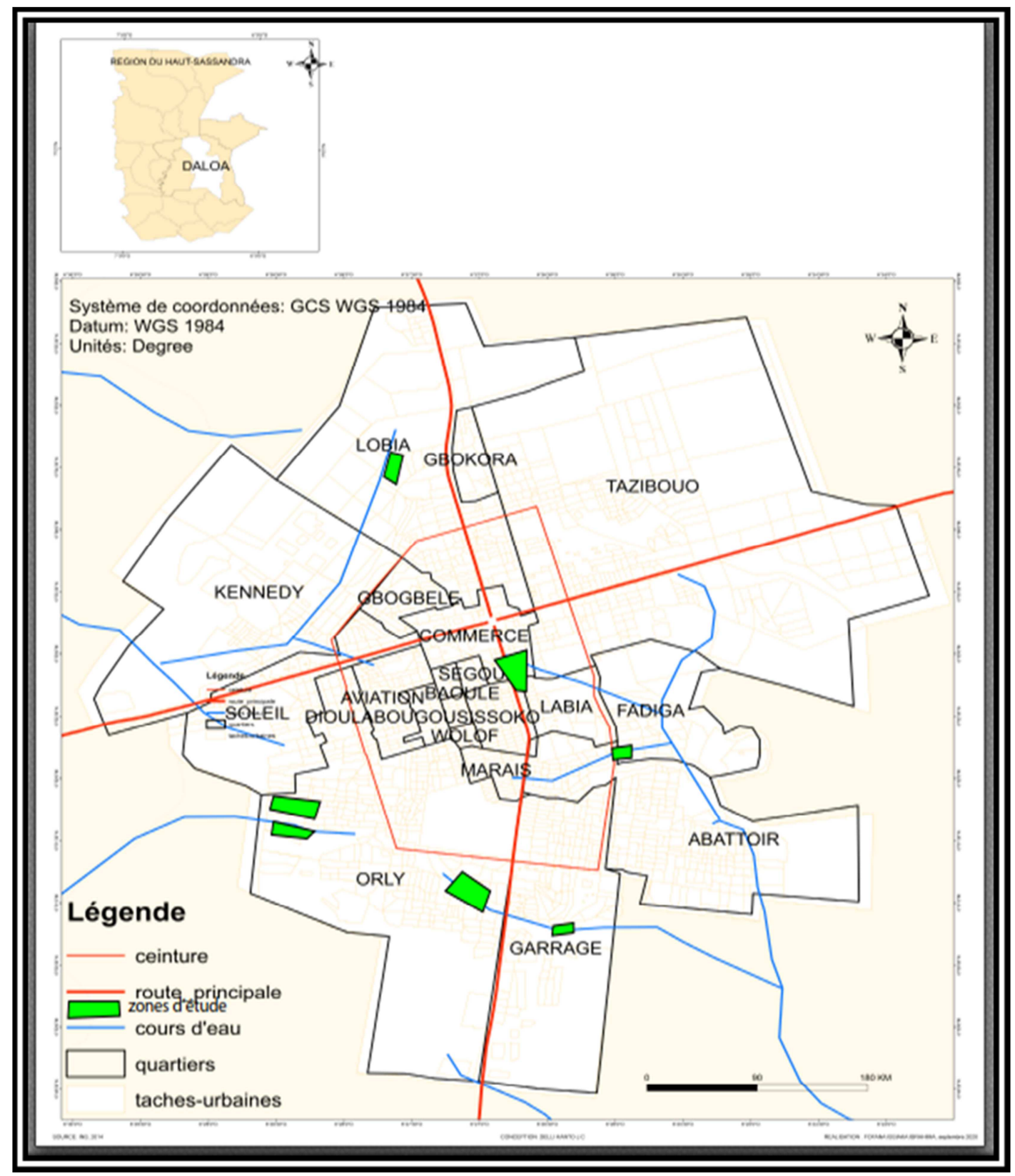

Figure 1. Presentation of study sites Units.

For each depth, we mixed E1, E2 and E3.

E1: sample from salad cultures;

E2: sample from onion leaf cultures;

E3: sample from cabbage cultures. 


\subsection{Statistical Analysis}

In our study, we carried out a principal component analysis (PCA), with a view to highlighting the relationships between variables on the one hand, the distribution of individuals taking into account all of their physicochemical characteristics (Belghiti, 2013) and to determine the possible vectors of pollution. PCA is a technique for representing data under certain algebraic and geometric criteria, its objective is to extract most of the information contained in the data tables and to provide a graphical representation that is easy to interpret given the data correlations. The statistical processing of the data is carried out by the STATISTICA version 7 software.

\section{3. pH Determination}

The $\mathrm{pH}$ was measured using a multimeter. The $\mathrm{pH}$ of the soil, or pHwater, is considered to be the equilibrium $\mathrm{pH}$ between the solid phase of a soil sample and the liquid phase represented by distilled water. It represents the acidity of the medium and reflects the concentration of $\mathrm{H}+$ ions in the soil. The pH-water is measured according to the ISO 10390 standard. $10 \mathrm{~g}$ of sol are suspended in $25 \mathrm{~mL}$ of ultra-pure water, stirred for 1 hour at 150 revolutions per minute on a back-and-forth stirring table of the Ping type. Pong 560, then left to stand for an hour. The $\mathrm{pH}$ is then measured using a $\mathrm{pH}$ meter.

\subsection{Organic Material}

The organic matter content is evaluated by the loss of mass of $1 \mathrm{~g}$ of the dry sample after heating to $525^{\circ} \mathrm{C}$ (determination of the loss on ignition of the sediments). The method applied is that of loss on ignition according to standard NF ISO 10694 (2000). It consists in weighing a sample of soil dried beforehand before its total calcination, then in weighing the mass of this sample after calcination. The organic matter content is determined from the mass $(\mathrm{m} 1)$ of the sample taken (dry soil) and that determined after passing in the oven $(\mathrm{m} 2)$.

$$
\% M O=\frac{m_{1}-m_{2}}{m_{1}}
$$

\subsection{Determination of Trace Elements}

Weigh $0.2 \mathrm{~g}$ of sediment into the Teflon flasks, add $5 \mathrm{ml}$ of $65 \%$ nitric acid then $2 \mathrm{ml}$ of hydrofluoric acid and leave to stand in the hood for 1 hour. Then add $2 \mathrm{ml}$ of hydrogen peroxide (30-33\%). Close the vials and place them on a hot plate for 3 hours at $120^{\circ} \mathrm{C}$. After this heating time, lower the flasks and add $10 \mathrm{ml}$ of $4 \%$ boric acid, close and heat for a further 1 hour. Let the vials cool under the hood. After cooling, put $10 \mathrm{ml}$ of $4 \%$ boric acid in the $50 \mathrm{ml} \mathrm{FALCON}$ tubes and transfer the contents of the Teflon vials into them and make up the volume to $50 \mathrm{ml}$ with distilled water. Make a blank under the same conditions but not containing a sample. The mineralized (liquid) thus obtained are ready to be injected into the device (AAS). Thus, aluminum, magnesium, calcium and zinc were determined by the flame method, lead, cadmium, arsenic, chromium and nickel by the furnace method and mercury by the hydride method.

\section{Results and Discussion}

\subsection{Results}

\subsubsection{Physicochemical Parameters in Sediments}

Table 1 gives the $\mathrm{pH}$ values measured for the different soil horizons of the three sites studied. We retain that this varies from 5.71 to 7.58 for the low bottom 1 , from 5.70 to 6.88 for the low bottom 2 and from 6.63 to 7.04 for the site 3 .

The percentages of organic matter obtained for the different sites 1,2 and 3 vary respectively from 13.18 to $41.87 \%$, from 1 to $45.05 \%$ and from 5.72 to $26.79 \%$ in site S1, the percentage is greater for profiles greater than $50 \mathrm{~cm}(\mathrm{P} 3(41.87 \%))$. Contrary to this, the basfond 2 (S2), with a more considerable organic fraction (P1 (45.05\%)) for the surface profiles between 0 and $15 \mathrm{~cm}$. The percentage of organic matter in the $\mathrm{S} 3$ site is substantially equal for the surface profiles (P1 (26.79\%)) and greater than $50 \mathrm{~cm}$ (P3 (25.65\%)).

In addition, the results of our study show that the trace elements studied are present in the sediments and in the various profiles. MTEs including aluminum, calcium and zinc are present in considerable quantities. On the other hand, low levels of cadmium, mercury and lead were noted, the contents of which in the various sediment profiles are less than $1 \mathrm{mg} / \mathrm{Kg}$.

Table 1. Physicochemical parameters in the lowlands of vegetable crops.

\begin{tabular}{|c|c|c|c|c|c|c|c|c|c|c|c|c|c|}
\hline & \multirow{2}{*}{ Stations } & \multirow{2}{*}{ pH } & \multirow{2}{*}{$\%$ MO } & \multicolumn{10}{|c|}{ MTE Concentrations (mg/Kg) } \\
\hline & & & & Al & As & $\mathrm{Ca}$ & Cd & $\mathbf{C r}$ & Hg & Mg & $\mathbf{N i}$ & $\mathbf{P b}$ & $\mathbf{Z n}$ \\
\hline \multirow{3}{*}{ shallows 1} & $\mathrm{P}_{1}$ & 7.58 & 13.18 & 12279.0 & 3.10 & 5008.1 & 0.33 & 16.43 & 0.16 & 185.8 & 21.86 & 0.61 & 499.15 \\
\hline & $\mathrm{P}_{2}$ & 5.71 & 15.94 & 12935.7 & 11.33 & 5432.3 & 0.47 & 20.91 & 1.34 & 198.8 & 22.08 & 0.79 & 601.7 \\
\hline & $\mathrm{P}_{3}$ & 7.37 & 41.87 & 11894.9 & 9.25 & 4928.6 & 0.15 & 24.90 & 1.04 & 98.66 & 9.32 & 0.59 & 570.1 \\
\hline \multirow{3}{*}{ shallows 2} & $\mathrm{P}_{1}$ & 5.37 & 45.05 & 11225.2 & 4.77 & 5482.82 & 0.59 & 25.09 & 0.21 & 324.63 & 22.77 & 0.57 & 83873 \\
\hline & $\mathrm{P}_{2}$ & 6.88 & 1 & 9664.23 & 1.81 & 4994.22 & 0.30 & 18.84 & 0.15 & 283.20 & 19.14 & 0.68 & 596.5 \\
\hline & $\mathrm{P}_{3}$ & 5.94 & 5.62 & 8653.34 & 11.15 & 4992.73 & 0.25 & 20.76 & 0.31 & 172.71 & 19.77 & 0.59 & 550.65 \\
\hline \multirow{3}{*}{ shallows 3} & $\mathrm{P}_{1}$ & 6.71 & 26.79 & 7682.39 & 5.45 & 4991.85 & 0.28 & 23.11 & 0.51 & 143.70 & 23.85 & 0.56 & 588.71 \\
\hline & $\mathrm{P}_{2}$ & 6.63 & 5.72 & 8723.85 & 1.82 & 4805.85 & 0.17 & 24.94 & 1.02 & 119.19 & 26.77 & 0.57 & 611.97 \\
\hline & $\mathrm{P}_{3}$ & 7.04 & 25.65 & 8055.68 & 3.09 & 4979.55 & 0.27 & 27.95 & 0.46 & 189.30 & 15.75 & 0.65 & 683.73 \\
\hline
\end{tabular}


Table 2. Correlation between the parameters studied in the lowland 1.

\begin{tabular}{|c|c|c|c|c|c|c|c|c|c|c|c|c|c|}
\hline & PR & pH & Al & As & $\mathrm{Ca}$ & Cd & $\mathrm{Cr}$ & $\mathrm{Hg}$ & Mg & $\mathbf{N i}$ & $\overline{\mathbf{P b}}$ & $\overline{\mathrm{Zn}}$ & $\%$ MO \\
\hline PR & 1 & -0.80 & -0.36 & 0.72 & -0.15 & -0.53 & 0.99 & 0.72 & -0.80 & -0.86 & -0.09 & 0.68 & 0.91 \\
\hline $\mathrm{pH}$ & & 1 & 0.85 & -0.16 & 0.71 & 0.93 & -0.78 & -0.16 & 1 & 0.99 & 0.67 & -0.10 & -0.97 \\
\hline $\mathrm{Al}$ & & & 1 & 0.38 & 0.97 & 0.98 & -0.33 & 0.39 & 0.85 & 0.79 & 0.96 & 0.44 & -0.72 \\
\hline As & & & & 1 & 0.58 & 0.21 & 0.74 & 0.99 & -0.16 & -0.26 & 0.63 & 0.99 & 0.36 \\
\hline $\mathrm{Ca}$ & & & & & 1 & 0.92 & -0.11 & 0.58 & 0.71 & 0.63 & 0.99 & 0.63 & -0.55 \\
\hline $\mathrm{Cd}$ & & & & & & 1 & -0.50 & 0.21 & 0.93 & 0.89 & 0.89 & 0.26 & -0.84 \\
\hline $\mathrm{Cr}$ & & & & & & & 1 & 0.74 & -0.78 & -0.84 & -0.06 & 0.69 & 0.89 \\
\hline $\mathrm{Hg}$ & & & & & & & & 1 & -0.16 & -0.26 & 0.628 & 0.99 & 0.36 \\
\hline $\mathrm{Mg}$ & & & & & & & & & 1 & 0.99 & 0.67 & -0.10 & -0.98 \\
\hline $\mathrm{Ni}$ & & & & & & & & & & 1 & 0.59 & -0.20 & -0.99 \\
\hline $\mathrm{Pb}$ & & & & & & & & & & & 1 & 0.67 & -0.50 \\
\hline $\mathrm{Zn}$ & & & & & & & & & & & & 1 & 0.30 \\
\hline$\% \mathrm{MO}$ & & & & & & & & & & & & & 1 \\
\hline
\end{tabular}

\subsubsection{Factor Analysis in the Lowlands 1}

The factor extraction was performed by the principal component method. Two factors whose eigenvalues are greater than 1 were retained according to the criterion of
KAISER [5]. They correspond to $100 \%$ of the total variance. The factor $F_{1}$ is the most important with an expressed variance of $78.48 \%$ and the factor $F_{2}$ with a variance of $21.52 \%$ (Table 3).

Table 3. Eigenvalues and percentage of cumulative expressed variance for the lowland 1.

\begin{tabular}{lllll}
\hline & Own values & \% total variance expressed & Cumulation of eigenvalues & Cumulative \% \\
\hline $\mathrm{F}_{1}$ & 6.39 & 63.89 & 6.39 & 63.89 \\
$\mathrm{~F}_{2}$ & 3.61 & 36.11 & 10.00 & 100.00 \\
\hline
\end{tabular}

Table 4. Coordinates of the various factors in the lowland 1.

\begin{tabular}{lll}
\hline & $\mathbf{F}_{\mathbf{1}}$ & $\mathbf{F}_{\mathbf{2}}$ \\
\hline $\mathrm{PR}$ & 0.82 & -0.57 \\
$\mathrm{pH}$ & -0.99 & -0.04 \\
$\mathrm{Al}$ & -0.83 & -0.56 \\
$\mathrm{As}$ & 0.19 & -0.98 \\
$\mathrm{Ca}$ & -0.69 & -0.73 \\
$\mathrm{Cd}$ & -0.92 & -0.39 \\
$\mathrm{Cr}$ & 0.80 & -0.60 \\
$\mathrm{Hg}$ & 0.19 & -0.98 \\
$\mathrm{Mg}$ & -0.99 & -0.04 \\
$\mathrm{Ni}$ & -0.99 & 0.07 \\
$\mathrm{~Pb}$ & 0.64 & 0.77 \\
$\mathrm{Zn}$ & -0.13 & 0.99 \\
$\% \mathrm{MO}$ & -0.99 & 0.17 \\
\hline
\end{tabular}

The factorial weights of the variables (Table 4) reflect their correlations with the extracted factors. The first factor $F_{1}$ contains the PR depth, chromium $(\mathrm{Cr})$, and lead $(\mathrm{Pb})$. The second factor is in association with lead $(\mathrm{Pb})$ and zinc $(\mathrm{Zn})$.

The projection of the variables in the factorial plane $\left(\mathrm{F}_{1}-\mathrm{F}_{2}\right)$ highlights a single group of parameters which notably contains \% $\mathrm{MO}, \mathrm{Ni}, \mathrm{pH}, \mathrm{Mg}, \mathrm{As}, \mathrm{Cd}, \mathrm{Al}$ and $\mathrm{Ca}$ (Figure 2).
However, the variation in depth (PR) is opposed to this group.

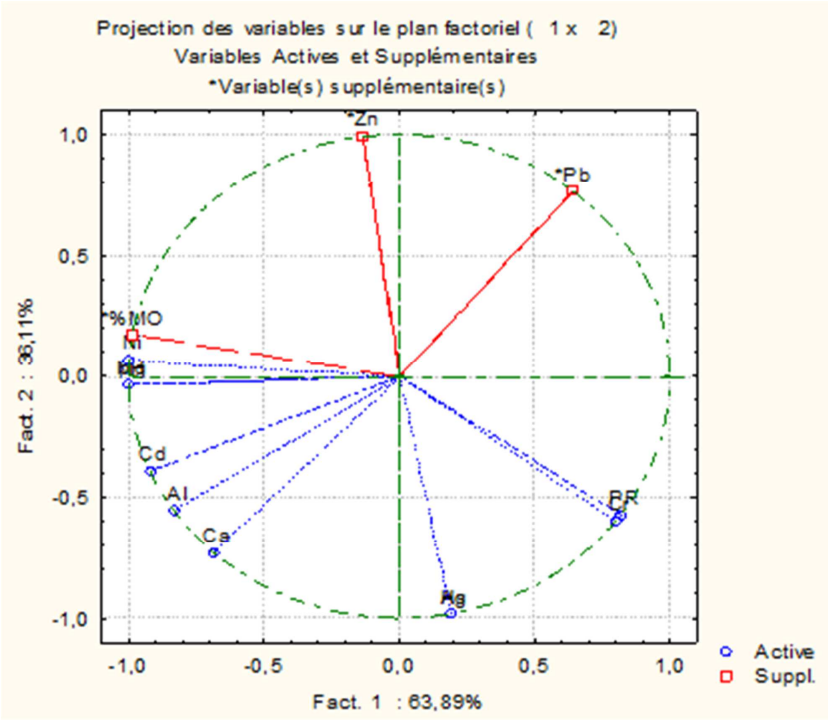

Figure 2. Principal component analysis of lowland sediments 1 in the factorial plane $F_{1}-F_{2}$.

Table 5. Correlation between the parameters studied in the lowland 2

\begin{tabular}{|c|c|c|c|c|c|c|c|c|c|c|c|c|c|}
\hline & pH & $\%$ MO & Hg & $\mathbf{P b}$ & Cd & As & $\mathrm{Cr}$ & $\mathbf{N i}$ & $\mathbf{C a}$ & Mg & Al & $\mathrm{Zn}$ & PR \\
\hline $\mathrm{pH}$ & 1 & 0.5 & -0.39 & 0.23 & 0.24 & 0.83 & 0.63 & 0.51 & 0.36 & -0.39 & -0.39 & 0.23 & 0.14 \\
\hline$\% \mathrm{MO}$ & & 1 & 0.64 & 0.97 & 0.97 & -0.11 & 0.97 & 0.99 & 0.99 & 0.64 & 0.64 & 0.97 & -0.81 \\
\hline $\mathrm{Hg}$ & & & 1 & 0.80 & 0.80 & -0.83 & 0.47 & 0.58 & 0.71 & 0.99 & 0.99 & 0.81 & -0.97 \\
\hline $\mathrm{Pb}$ & & & & 1 & 0.99 & -0.35 & 0.89 & 0.95 & 0.98 & 0.81 & 0.81 & 1 & -0.93 \\
\hline $\mathrm{Cd}$ & & & & & 1 & -0.34 & 0.90 & 0.95 & 0.90 & 0.80 & 0.80 & 0.99 & -0.92 \\
\hline As & & & & & & 1 & 0.10 & -0.04 & -0.21 & -0.83 & -0.83 & -0.34 & 0.67 \\
\hline $\mathrm{Cr}$ & & & & & & & 1 & 0.99 & 095 & 0.47 & 0.47 & 0.89 & -0.67 \\
\hline $\mathrm{Ni}$ & & & & & & & & 1 & 0,98 & 0.58 & 0.58 & 0.95 & -0.77 \\
\hline $\mathrm{Ca}$ & & & & & & & & & 1 & 0.71 & 0.71 & 0.98 & -0.86 \\
\hline $\mathrm{Mg}$ & & & & & & & & & & 1 & 1 & 0.8 & -0.97 \\
\hline
\end{tabular}




\begin{tabular}{|c|c|c|c|c|c|c|c|c|c|c|c|c|c|}
\hline & pH & $\%$ MO & $\mathrm{Hg}$ & $\mathbf{P b}$ & Cd & As & $\mathrm{Cr}$ & $\mathbf{N i}$ & $\mathbf{C a}$ & Mg & Al & $\mathrm{Zn}$ & PR \\
\hline $\mathrm{Al}$ & & & & & & & & & & & 1 & 0.81 & -0.96 \\
\hline $\mathrm{Zn}$ & & & & & & & & & & & & 1 & -0.93 \\
\hline PR & & & & & & & & & & & & & 1 \\
\hline
\end{tabular}

Table 6. Eigenvalues and cumulative expressed percentage variance for lowland sediments 2.

\begin{tabular}{lllll}
\hline & Own values & \% total variance expressed & Cumulation of eigenvalues & Cumulative\% \\
\hline$F_{1}$ & 7.11 & 71.11 & 7.1 & 71.11 \\
$F_{2}$ & 2.89 & 28.89 & 10.00 & 100.00 \\
\hline
\end{tabular}

Table 7. Coordinates of the various factors in the lowland 2.

\begin{tabular}{lll}
\hline & $\mathbf{F}_{\mathbf{1}}$ & $\mathbf{F}_{\mathbf{2}}$ \\
\hline $\mathrm{pH}$ & -0.23 & -0.97 \\
$\% \mathrm{MO}$ & -0.97 & -0.24 \\
$\mathrm{Hg}$ & -0.80 & 0.59 \\
$\mathrm{~Pb}$ & -0.99 & 0.01 \\
$\mathrm{Cd}$ & -0.99 & -0.01 \\
$\mathrm{As}$ & 0.34 & -0.94 \\
$\mathrm{Cr}$ & -0.90 & -0.43 \\
$\mathrm{Ni}$ & -0.95 & -0.30 \\
$\mathrm{Ca}$ & -0.98 & -0.14 \\
$\mathrm{Mg}$ & -0.80 & 0.59 \\
$\mathrm{Al}$ & 0.80 & -0.59 \\
$\mathrm{Zn}$ & 0.99 & -0.01 \\
$\mathrm{PR}$ & -0.92 & 0.37 \\
\hline
\end{tabular}

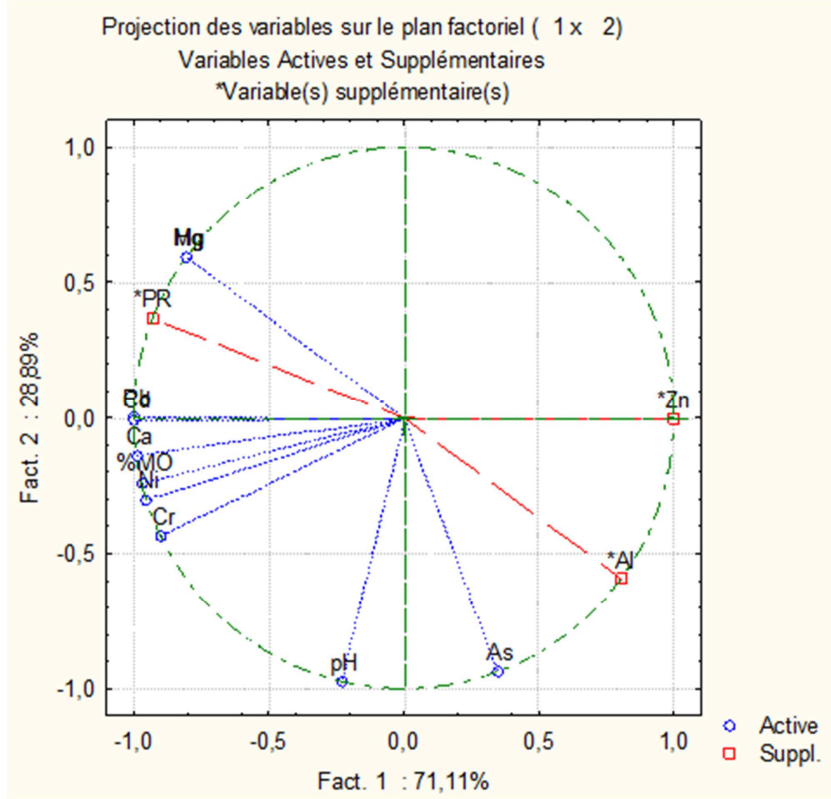

Figure 3. Principal component analysis of lowland sediments 2 in the factorial plane $F_{1}-F_{2}$.

The projection of the variables in the factorial plane $\left(\mathrm{F}_{1}-\mathrm{F}_{2}\right)$ highlights a single group of parameters which notably contains $\mathrm{Mg}, \mathrm{PR}, \mathrm{Pb}, \mathrm{Cd}, \mathrm{Ni}, \mathrm{Cr}, \% \mathrm{MO}, \mathrm{Ca}, \mathrm{Hg}$.

Table 8. Eigenvalues and percentage of cumulative expressed variance for the sediments of the Lowland 3.

\begin{tabular}{llll}
\hline Own values & $\begin{array}{l}\text { \% total variance } \\
\text { expressed }\end{array}$ & $\begin{array}{l}\text { Cumulation of } \\
\text { eigenvalues }\end{array}$ & Cumulative\% \\
\hline 6.93 & 69.30 & 6.93 & 69.30 \\
3.07 & 30.70 & 10.00000 & 100.0 \\
\hline
\end{tabular}

Table 9. Coordinates of the different factors in the lowland 3.

\begin{tabular}{lll}
\hline & $\mathbf{F}_{\mathbf{1}}$ & $\mathbf{F}_{\mathbf{2}}$ \\
\hline$\% \mathrm{MO}$ & -0.91 & 0.42 \\
$\mathrm{Ph}$ & -0.91 & -0.42 \\
$\mathrm{As}$ & -0.43 & 0.90 \\
$\mathrm{Ca}$ & -0.88 & 0.47 \\
$\mathrm{Cd}$ & -0.88 & 0.47 \\
$\mathrm{Cr}$ & -0.53 & -0.84 \\
$\mathrm{Hg}$ & -0.96 & -0.26 \\
$\mathrm{Mg}$ & 0.94 & -0.33 \\
$\mathrm{Ni}$ & -0.74 & -0.67 \\
$\mathrm{~Pb}$ & 0.94 & 0.35 \\
$\mathrm{Zn}$ & 0.66 & 0.76 \\
$\mathrm{Al}$ & -0.70 & 0.71 \\
$\mathrm{PR}$ & -0.42 & 0.91 \\
\hline
\end{tabular}

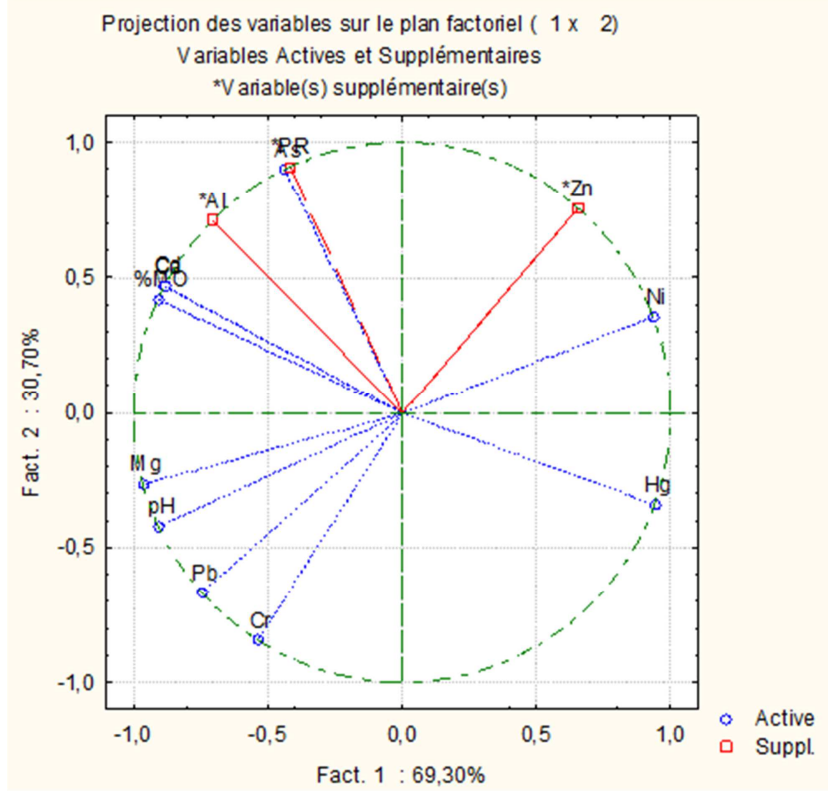

Figure 4. Principal component analysis of lowland sediments 3 in the factorial plane $F_{1}-F_{2}$.

The projection of the variables in the factorial plane $\left(\mathrm{F}_{1}-\mathrm{F}_{2}\right)$ reveals three groups of parameters. The first group contains $\%$ $\mathrm{MO}, \mathrm{Al}, \mathrm{As}, \mathrm{Cd}, \mathrm{PR}$ and the second $\mathrm{pH}, \mathrm{Pb}, \mathrm{Mg}, \mathrm{Cr}$.

\subsubsection{Study of the Mobility of Metals in the Lowlands 3}

From the study of the correlation, we note an association between organic matter and Chromium. Also, there is an association between $\mathrm{pH}$ and Aluminum, Calcium, Cadmium, Nickel and Lead. Interestingly, there is a positive and significant correlation between Arsenic and Chromium with depth. We see that Aluminum and Calcium are correlated 
with the same elements which are Cadmium and Lead.

\subsection{Discussion}

The soil $\mathrm{pH}$ is a very influential parameter, which plays a major role in many physicochemical reactions such as precipitation/solubilization reactions or adsorption/desorption on the solid phases of the soil and the speciation of metals in aqueous solution. Our study has shown that the sediments from the different sites have a $\mathrm{pH}$ that varies between 5 and 8 . These different $\mathrm{pH}$ values obtained will have a notable influence on the solubility or even the mobility of certain MTEs studied during our study. Indeed, the solubility of chemically stable elements in the form of cations such as $\mathrm{Cd}$, $\mathrm{Pb}$ and $\mathrm{Zn}$ decreases when the $\mathrm{pH}$ increases. Conversely for chemically stable elements in the form of anions such as $\mathrm{Cr}$ (VI), As and Se, solubility increases with $\mathrm{pH}[6]$. In lowlands 1,2 and 3, the strong correlations observed at the level of $\mathrm{pH}$ values and metallic trace elements testify to the fact that the $\mathrm{pH}$ of the soil has a very strong influence on the soil's capacity to retain metals, but also to release them. Lowering the $\mathrm{pH}$ would therefore have favored the mobility of metals. These results are in agreement with those obtained by Kouassi in the soil of the Akouédo landfill (Abidjan) [7].

In addition, no correlations were noted between the $\mathrm{pH}$ and the percentage of organic matter in lowlands 2 and 3 (Table 7 and 8). For all the organic constituents, two groups are generally recognized as being the most reactive: humic substances (HS): humic acids, fulvic acids and humin [8]. and organic acids of low molecular masses $[9,10]$. From the results of our study, we will have a solubility of the fraction of humic acids in the different sediments. On the other hand, fluvic acids are soluble in the shallow sediments 3 and those obtained at a depth greater than $50 \mathrm{~cm}$.

In addition, during our study, we note the presence of MTEs studied in the various sediments at varying concentrations. Also, the statistical processing of different data including their correlations allows us to make several observations.

In lowland sediments 3 , in addition to the correlation between the $\mathrm{pH}$ and $\% \mathrm{MO}$, we note associations between it and the arsenic $\mathrm{As}, \mathrm{Cd}, \mathrm{Hg}$. This suggests that the acidity of the medium at a notable influence on the reactivity of the substances which constitute the organic matter by consequence the mobility of the MTE which are bound to this one in particular arsenic, cadmium and mercury. $\mathrm{Cd}$ preferentially accumulates in horizons rich in organic matter [11] and can migrate with the organometallic complex. In addition, we have noted associations between $\mathrm{pH}$ and calcium, which is one of the constituents of calcium carbonate. However, this is involved in the fixation of metallic trace elements, either by adsorption or by precipitation of hydroxides or carbonates or even by insertion into the $\mathrm{CaCO}_{3}$ network [12]. In addition, we have associations between calcium, cadmium and mercury. It could be deduced from this that these trace elements would be linked to carbonates and the $\mathrm{pH}$ would influence their various reactions with them.
In the sediments of the lowland 2, we have the same information as those of the lowland1. However, organic matter is associated with most of the trace elements studied. These elements are either linked to the organic matter or incorporated into it. In addition, the associations observed between calcium, aluminum, magnesium, mercury and lead suggest the presence of an argillaceous fraction in lowland sediments 2 composed of carbonates bound to these MTEs either by adsorption by precipitation or incorporated therein.

Site 1, on the other hand, does not show an association between $\mathrm{pH}$ and organic matter. However, we note correlations between $\mathrm{pH}$ and aluminum and calcium which are the building blocks of the clay fraction of the soil. Also, are they associated with cadmium, magnesium, nickel, lead, mercury and lead. This suggests that these MTEs are not only linked to the clay fraction of the soil but the physicochemical parameters of the soil, in particular the $\mathrm{pH}$, govern their mobility.

A pH greater than 5 and a soil with an organic matter content of at least $5 \%$ favor the accumulation of lead [13]. In this case, oxidation state II lead, which exists in a given environment, is slowly incorporated into clay minerals and organic matter [14].

In the soil, the concentration of MTE varies with depth. Microelements from external inputs will accumulate on the surface. Their concentration will therefore decrease with depth and, in cultivated soils, mark a clear discontinuity above the cultivated layer [15]. We observed this discontinuity in the MTE contents in the sediments of the various sites studied. Indeed, the study of the correlation showed that only Arsenic and Chromium are in association with the variation of the depth in the shallows 2 and 3 . However in the sediments of the shallows, Arsenic, Chromium, Mercury and Zinc correlate with soil depth.

\section{Factor analysis}

The projection of the various parameters studied in the factorial plane $\mathrm{F}_{1}-\mathrm{F}_{2}$ for the sediments of the various sites made it possible to highlight a single group of parameters which contains\% $\mathrm{MO}, \mathrm{Ni}, \mathrm{pH}, \mathrm{Cd}, \mathrm{Al}$ and $\mathrm{Mg}$. This demonstrates that nickel, cadmium, and magnesium are not only linked to the clayey and organic fraction of the sediments, but their mobility is influenced by the $\mathrm{pH}$. In addition, the factor F1 expresses the vertical dynamics of the MTEs of $\mathrm{Cr}$ and $\mathrm{Pb}$.

In site 2 , factors $F_{1}$ and $F_{2}$ respectively demonstrate the clayey and organic fraction of the sediments. Indeed, $F_{1}$ and $\mathrm{F}_{2}$ are respectively associated and aluminum $\mathrm{Al}$ with magnesium which is a constituent element of the clay and organic fraction of the sediments.

The projection in the $F_{1}-F_{2}$ plane highlights a single class. This class contains organic matter and aluminum. Therefore, the trace elements of this group including cadmium $(\mathrm{Cd})$, chromium $(\mathrm{Cr})$, nickel $(\mathrm{Ni})$, lead $(\mathrm{Pb})$ are bound to organic matter and to the clay fraction of the sediments.

Factorial analysis of data obtained for lowland 3 reveals two distinct classes. The first class which contains the percentage of organic matter, depth, aluminum, arsenic and 
cadmium. This class reflects a vertical dynamism of MTEs in the profiles. In addition, they could be fixed by organic matter through complexation reactions.

The second class shows that the mobility of chromium, magnesium, and lead is influenced by $\mathrm{pH}$.

\section{Conclusion}

At the end of this study, we note that the majority of the sediments studied are acidic with a more or less important organic fraction in the different sediment profiles. In addition, the trace metal elements studied including aluminum, arsenic, calcium, chromium, mercury, magnesium, nickel, lead and zinc are present in these lowlands of vegetable crops. Consequently, there are risks of metallic bioaccumulation of its MTEs in market garden products that can cause health risks to the populations who consume its products.

In addition, our study showed Arsenic, Chromium, Mercury and Zinc have a mobility function of different sediment profiles influenced in particular by $\mathrm{pH}$. In addition, it is noted that $\mathrm{Cd}, \mathrm{Cr}, \mathrm{Mg}, \mathrm{Ni}, \mathrm{Pb}$ are linked to organic matter and to the clay fraction of the sediments. However, their mobility would be influenced by $\mathrm{pH}$.

To deepen our research, we would like to study the influence of other physicochemical parameters such as redox potential, particle size, CEC, CEA on the mobility of ETM in soils. Also study the bioavailability of ETMs in plants in order to assess their health risks on populations.

\section{References}

[1] Kra, K. V., Problématique Maraîchère Induite Par La Nouvelle Dynamique Foncière Autour Des Bas-Fonds Urbains À Bouaké (Côte D'ivoire), 2018. Université Alassane Ouattara (Bouaké, Côte d'Ivoire), Thèse.

[2] Fournet, F., Gestion de l'espace et schistosomose urinaire à Daloa (Côte d'Ivoire), N'Guessan N. A. \& Cadot E. (1), 2002. $33 p$.

[3] Lenard, A. and Colin, G., Synthèse bibliographique sur la mobilité des éléments traces dans les sols et l'utilisation de la stabilisation physicochimique comme technique de gestion in situ des sites contaminés, 2014, Université de Liège.
[4] Bashar, M. A. Butterflies of Bangladesh: A broad approach for nature lovers (EBBL Red-List and butterfly activities). 1st ed. BCTF Publications, Vol. 2, 177, 2015.

[5] KAISER, H. F., The varimax criterion for analytic rotation in factor analysis. Pyrometrical, 23, 187-200, 1958.

[6] Deneux-Mustin, S., Mobilité et transfert racinaire des éléments en traces: influence des micro-organismes du sol. Tec \& Doc. - Lavoisier, Paris, 2003.

[7] Kouassi, K. I., Goné, D. L., Savané, I., Kouassi, E. A., Koffi, K., Goula, B. T. A. et Diallo, M., Mobilité relative des métaux lourds issus de la décharge d'Akouédo et risque de contamination de la nappe du continental Terminal (AbidjanCôte d'Ivoire). Afrique Science 02: 39-56, 2006.

[8] Calvet, R. et Msaky, J. J. Facteurs influençant la détermination expérimentale des quantités de cations métalliques traces adsorbées par un matériau terreux. In: Science du sol, Vol. 2, 1, 1-14, 1990.

[9] Harter, R. D., and Naidu, R. Rôle de la complexation metalorganique dans la sorption des métaux par les sols. Advances in Agronomy, volume 55, 219-263, 1995.

[10] Strobel, B. W. Influence de la végétation sur les aides carboxyliques de bas poids moléculaires dans la solution du sol-un examen. Geoderma, 99, 3-4, 169-198, 2001.

[11] Bisson, M. Fiche de données toxicologiques et environnementales des substances chimiques. Cuivre et ses dérivées, 2005.

[12] Bur, T. Impact anthropiques sur les éléments traces métalliques dans les sols agricoles me Midi-Pyrénés. Implications en termes de limites et de charges critiques. Thèse de Doctorat, Université de Toulouse, Toulouse France, 2008.

[13] Pichard, A. Fiche de données toxicologiques et environnementales des substances chimiques: Zinc et ses dérivés». INERIS-DRC-01-25590 - ETSC-APi/SD, $\mathrm{N}^{\circ} 00 \mathrm{df} 259,62 \mathrm{p}, 2003$.

[14] Pitt, R., Clark, S., Parmer, K. Potential groundwater contamination from intentional and nonintentional stormwater infiltration. Springfield (USA): US Environmental Protection Agency, 187 p. 1994.

[15] Juste, C., Chassin, P., Gomez, A., Linères, M., Mocquot, B. Les micro-polluants métalliques dans les boues résiduaires des stations d'épuration urbaines, Convention ADEME-INRA, ADEME éd., 209p (1995). 